\title{
Functionally-inactive and immunogenic Tat, Rev and Nef DNA vaccines derived from sub-Saharan subtype $C$ human immunodeficiency virus type 1 consensus sequences
}

\section{Thomas J. Scriba a, Jan zur Meged ${ }^{\mathrm{c}}$, Richard H. Glashoff ${ }^{\mathrm{b}}$, Florette K. Treurnicht ${ }^{\mathrm{d}}$, Susan W. Barnett ${ }^{\mathrm{c}}$ and Estrelita Janse van Rensburg}

${ }^{a}$ The Peter Medawar Building for Pathogen Research, Nuffield Department of Clinical Medicine, University of Oxford, Oxford, UK

${ }^{b}$ Department of Medical Virology, University of Stellenbosch and National Health Laboratory Service, Tygerberg, South Africa ${ }^{\mathrm{C}}$ Chiron Corporation, Emeryville, CA 94608, USA

${ }^{\mathrm{d}}$ Division of Medical Virology, Department of Clinical Laboratory Sciences, Institute of Infectious Diseases and Molecular Medicine, University of Cape Town, South Africa

\begin{abstract}
The efficacy of cellular immune responses elicited by HIV vaccines is dependent on their strength, durability and antigenic breadth. The regulatory proteins are abundantly expressed early in the viral life cycle and CTL recognition may bring about early killing of infected cells. We synthesised DNA vaccine constructs that encode consensus HIV-1 subtype C Tat, Rev and Nef proteins. Proteins carrying inactivating mutations were tested for functional activity and highly expressing, inactive Tat, Rev and Nef mutants were identified and their reading frames fused into a TatRevNef cassette. Single- and polygene Tat, Rev and/or Nef constructs were immunogenic in BALB/c mice. These constructs may serve to increase the antigenic breadth for an HIV-1 vaccine that is relevant for subSaharan Africa.
\end{abstract}




\section{Article Outline}

1. Introduction

2. Materials and methods

2.1. Vaccine strain selection

2.2. Expression plasmid construction

2.3. Generating regulatory protein-specific mouse serum

2.4. Cells, transfections and immunoblotting

2.5. Functionality assays

2.6. Statistical Analysis

2.7. Immunogenicity studies

3. Results

3.1. Consensus sequences as vaccine strains

3.2. Construction and in vitro expression of wild-type and codon-optimized tat, rev and nef genes.

3.3. Identification of non-functional Tat, Rev and Nef-expressing plasmids

3.4. Assembly and expression of a non-functional TatRevNef DNA vaccine cassette

3.5. Immunogenicity assessment

4. Discussion

Acknowledgements

References

\section{Introduction}

Sub-Saharan Africa is burdened with the overwhelming majority of human immunodeficiency virus type 1 infections worldwide, which at the end of 2002 amounted to 29.4 million out of a global total of 42 million Of the number of global infections, more than half are caused by HIV-1 subtype C [2] and of the total number of infections in southern Africa, more than $94 \%$ are caused by HIV-1C [3]. The extremely high 
prevalence rates in the southern countries of Africa continuously underscore the desperate need for a vaccine that would impact on the rapid spread of the virus.

Over recent years, many studies have demonstrated the essential role of long-lasting $\mathrm{CD}^{+}$cytotoxic T lymphocyte (CTL) responses in HIV vaccine protection. HIV-1specific CTL responses have been shown to control viral load during acute and asymptomatic infection [4], [5], [6], [7] and [8] and are inversely correlated with disease progression [9]. Moreover, strong and cross-reactive CTL responses have been associated with resistance to HIV-1 infection in highly exposed, seronegative commercial sex workers in Kenya and the Gambia [10], [11] and [12]. However, the identification of viruses that escape from CTL and thus evade the immune system [13] and [14] has highlighted the need for such vaccine-elicited CTL responses to recognize an array of epitopes from multiple HIV-1 antigens. An effective HIV-1 vaccine may thus require strong humoral and cellular immune responses to multiple viral antigens including structural and regulatory proteins.

The regulatory proteins Tat, Rev and Nef are expressed early during the viral life cycle [15] and CTL recognition of these antigens may effect killing of infected cells prior to completion of the viral life cycle and mature virion production [16] and [17]. Tat, Rev and/or Nef-specific immune responses have been demonstrated to correlate with nonprogression or even protection from disease [14], [18], [19] and [20]. However, these proteins perform intrinsic functions that may raise safety and suitability concerns when introduced as vaccines. Tat acts as viral transactivator and has a number of effects on cells such as upregulation of chemokine receptor expression [21] and overproduction of interferon- $\alpha$ [22]. The Rev protein regulates viral gene expression by mediating nuclear export of incompletely spliced viral RNAs [23]. Nef acts on a great number of cellular pathways and effects a multitude of alterations that collectively seem to provide an optimal environment for viral replication. These include increasing virion infectivity [24], downregulation of cell surface CD4 [25] and MHC-I [26] expression and interference of $\mathrm{T}$ cell transduction and activation through numerous complex interactions (reviewed in reference [27]). 
A large number of studies have served to identify inactivating mutations and functional domains of the regulatory proteins Tat, Rev and Nef. Consequently, numerous immunogens and therapeutic agents based on mutated Tat, Rev and Nef have been developed and in some cases have shown to be promising. The inactivation of Tat by mutation of cysteine residues at positions 22, 25, 27 and 37 was first shown by Garcia et al. [28] and Ruben et al. [29] and TatC22 has since been developed as prophylactic and/or therapeutic vaccine [30], [31] and [32]. Similarly, two inactivating mutations termed M5 and M10 were identified in the Rev protein by Malim et al. [33]. RevM10 has since been developed as gene therapy agent and was shown to be clinically safe in human trials [34] and [35]. While Nef has also been shown to be a promising vaccine component, studies have demonstrated that inactivity of its intrinsic functions are abrogated in Nef proteins lacking myristoylation [36] or carrying, among a number of other mutations, the D123G [37] and LL165AA [38] and [39] mutations. Notably, to our knowledge, all mutational analysis of Tat, Rev and Nef has been done on proteins encoded by subtype B viruses.

As candidate components of a multipronged prime-boost vaccine strategy, we designed and synthesised codon-optimized DNA plasmid constructs that encode South African HIV-1 subtype C consensus Tat, Rev and Nef proteins. As these previous functional studies have been conducted on subtype B gene sequences, it was important to determine whether previously described inactivating mutations were applicable to similar gene constructs based on subtype $\mathrm{C}$ sequences. Thus, these genes were mutated to abrogate their respective undesirable protein activities and tested for functional inactivity to identify candidate subtype $\mathrm{C}$ Tat, Rev and Nef immunogens. In addition, immunogenicity of mutated, codon-optimized gene constructs was compared to the immunogenicity of wild-type functional genes in a mouse model.

\section{Materials and methods}

2.1. Vaccine strain selection 
We previously isolated and characterized 15 HIV-1 subtype C isolates from South Africa designated TV001 through TV010, TV012-TV014, TV018 and TV019 [40], [41], [42], [43] and [44]. The Tat, Rev and Nef amino acid sequences of 14 of these 15 subtype C isolates were used to derive respective consensus sequences (designated TV Cons) by taking the most prevalent residue for each amino acid position across the reading frames of the three regulatory proteins. Amino acid distances were calculated with the Kimura distance matrix [45] using the Phylip program PROTDIST.

\subsection{Expression plasmid construction}

Wild-type tat, rev and nef genes encoding proteins that most closely resemble the amino acid sequences of the respective TV Cons sequences (tat: TV019, rev: TV010, nef: TV002) were PCR amplified and cloned over SalI (XhoI for nef) and EcoRI sites into the pCMVKm2 plasmid vector as described previously [46]. The second exon of tat and first exon of rev were assembled from synthetic oligomers and cloned in-frame with the amplified exons over the KpnI and AvrII sites, respectively. Codon-optimized, synthetic gene constructs encoding the consensus TV Cons Tat, Rev and Nef sequences were also made by PCR assembly of 50mer oligonucleotides and cloned into the pCMVKm2 vector over SalI and EcoRI sites. Optimized initiation and termination codon contexts were also employed in these plasmid constructs [47] and [48]. Mutations (Table 1) were induced by oligonucleotide-based site-directed mutagenesis using the QuikChange Site-Directed Mutagenesis Kit (Stratagene, CA, USA). As potential polyprotein immunogen, the reading frames of the tat, rev and nef genes were fused to form a TatRevNef cassette $\left(\mathrm{pCTatRevNef} \mathrm{ZA}_{\mathrm{ZA}}\right.$ ) that incorporates mutations that inactivate the respective functions of the three proteins. The coding sequences of all plasmid constructs were verified by DNA sequencing. 


\begin{tabular}{|c|c|c|c|c|}
\hline \multirow[t]{2}{*}{ Construct name } & \multicolumn{2}{|l|}{ Sequence } & \multirow[t]{2}{*}{ Mutations } & \multirow[t]{2}{*}{ References } \\
\hline & Strain & $\begin{array}{l}\text { Wild-type/ } \\
\text { codon-optimized }\end{array}$ & & \\
\hline pTatwT ZA & TV019 & Wild-type & - & \\
\hline pTatopT ZA & Consensus & Codon-optimized & - & \\
\hline pTat $_{\mathrm{C} 22} \mathrm{ZA}$ & Consensus & Codon-optimized & $\mathrm{C} 22 \mathrm{G}$ & \\
\hline pTat $_{\mathrm{C} 37} \mathrm{ZA}$ & Consensus & Codon-optimized & $\mathrm{C} 37 \mathrm{~S}$ & $\begin{array}{l}\text { Garcia et al., 1988; Ruben } \\
\text { et al., } 1989\end{array}$ \\
\hline pTatc22C37ZA & Consensus & Codon-optimized & $\mathrm{C} 22 \mathrm{G} ; \mathrm{C} 37 \mathrm{~S}$ & \\
\hline pRevwtZA & TV010 & Wild-type & - & \\
\hline pRev ${ }_{M s M 10} Z A$ & Consensus & Codon-optimized & KR38DL; IE78DL & Malim et al., 1989 \\
\hline pNefwT $Z$ ZA & TV002 & Wild-type & - & \\
\hline pNefopT $\mathrm{ZA}$ & Consensus & Codon-optimized & - & \\
\hline pNef.myrD124ZA & Consensus & Codon-optimized & $\mathrm{G} 2 \mathrm{~A} ; \mathrm{D} 124 \mathrm{G}$ & $\begin{array}{l}\text { Niederman et al., 1993; Liu } \\
\text { et al., } 2000\end{array}$ \\
\hline pNef-myrD124LLAA ZA & Consensus & Codon-optimized & G2A; D124G; LL165AA & $\begin{array}{l}\text { Niederman et al., 1993; Liu } \\
\text { et al., 2000; Bresnahan et al., } \\
\text { 1998; Greenberg et al., } 1998\end{array}$ \\
\hline pCTatRevNef $f_{Z A}$ & Consensus & Codon-optimized & $\begin{array}{l}\text { TatC22G, C37S; RevKR38DL, } \\
\text { IE78DL; NefG2A; NefD124G; } \\
\text { NefLL165AA }\end{array}$ & as above \\
\hline
\end{tabular}

2.3. Generating regulatory protein-specific mouse serum

To generate polyclonal antibody serum specific for subtype C Tat, Rev and Nef, 6 to 8week-old female CB6F1 mice (10 per group) were immunized intramuscularly on two occasions with a 4 week interval with $75 \mu$ g naked endotoxin-free plasmid DNA in sterile

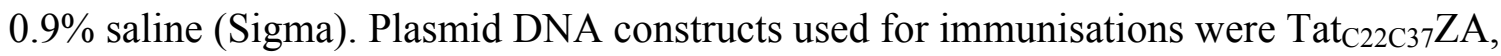
$\operatorname{Rev}_{\mathrm{M} 5 \mathrm{M10}} \mathrm{ZA}$ and Nef-myrD124ZA for Tat, Rev and Nef, respectively. Two weeks postsecond immunization, blood was collected by cardiac puncture and serum pooled for each group.

\subsection{Cells, transfections and immunoblotting}

Human embryonal kidney cells (293, ATCC 45504) and 293T (kindly donated by Ms Hanna Feenstra, Dept. Med. Biochemistry, Tygerberg, RSA) and HeLa cells (ATCC CCL-2) were propagated in Dulbecco's modified Eagles medium (DMEM, Gibco, Rockville, MD, USA) supplemented with 10\% fetal calf serum (FCS, Delta Bioproducts, Kempton Park, RSA), 100mg/L penicillin and streptomycin (Novo Nordisk (Pty.) Ltd., Johannesburg, RSA). One day prior to transfection, 293 and 293 T cells were plated at 1.4 
$\times 10^{6}$ cells and HeLa cells at $5 \times 10^{6}$ cells per $35 \mathrm{~mm}$ well. For transfections, DMEM was replaced with serum-free medium (OPTImem I Reduced Serum Medium, Gibco, Rockville MD, USA). Cells were transfected with plasmid DNA in $10 \mu 1$ Mirus TransITLT1 polyamine transfection reagent (Panvera, Madison, WI, USA) in $100 \mu 1$ OPTImem per well, following the manufacturers protocol. Eighteen microlitres of cell lysate or $10 \mu \mathrm{l}$ of Full-Range Rainbow Marker (Amersham-Pharmacia Biotech, Buckinghamshire, UK) were loaded on a NuPage Novex 4-12\% BisTris SDS gel (Invitrogen, Groningen, The Netherlands) and electrophoresed in NuPage MOPS SDS running buffer. Following SDS-PAGE, proteins were transferred onto a nitrocellulose membrane $(0.2 \mu \mathrm{m}$ pore size, Invitrogen) in NuPage Transfer Buffer containing 10\% Methanol. Subtype C Tat, Rev or Nef-specific polyclonal mouse serum was used as primary antibody. The secondary antibody was horseradish peroxidase (HRP)-conjugated Goat anti-Mouse IgG (Zymed, San Francisco, USA). Protein bands were visualized by chemo-luminescence using ECLPlus as directed by the manufacturer (Amersham-Pharmacia Biotech, Buckinghamshire, UK).

\subsection{Functionality assays}

Tat functionality was assayed as described by Kuppuswamy et al. [49]. Briefly, 293T and HeLa cells were co-transfected with $1 \mu \mathrm{g}$ pLTR-CAT reporter plasmid [50], $1 \mu \mathrm{g}$ tat expression plasmid and $0.5 \mu \mathrm{g} \mathrm{pSV- \beta Gal} \mathrm{internal} \mathrm{control} \mathrm{plasmid} \mathrm{(Promega,} \mathrm{Madison,}$ WI, USA) as described above. Cell lysates were harvested $24 \mathrm{~h}$ post-transfection and CAT enzyme levels were determined using a CAT ELISA as directed by the manufacturer (Roche Diagnostics, GmbH, Germany).

Rev functionality was determined in a cotransfection assay first described by Hope et al. [51]. One microgram of the pDM128 reporter plasmid (kindly donated by Prof. Thomas Hope) was co-transfected with $1 \mu \mathrm{g}$ rev expression plasmid and $0.5 \mu \mathrm{g} \mathrm{pSV- \beta Gal} \mathrm{internal}$ control plasmid. Cell lysate harvesting was performed as described for Tat.

The CD4 and MHC-I downregulation functions of Nef were assessed in a cotransfection assay adapted from the one described by Goldsmith et al. [52]. Briefly, 293 cells were co- 
transfected with $1 \mu \mathrm{g}$ nef-expression plasmid, $0.5 \mu \mathrm{g}$ pcDNA-hCD4 plasmid and $1 \mu \mathrm{g}$ pEGFP-N1 DNA (Clonetech, Palo Alto, CA) as described above. Forty-eight hours posttransfection, cells were treated with 2\% EDTA, washed with PBS and stained with allophycocyanin (APC)-conjugated anti-human CD4 and R-phycoerythrin (PE)conjugated anti-HLA-A,B,C antibodies (BD Biosciences, San Diego, CA, USA). Cell surface CD4 and MHC-I expression levels were determined on GFP-positive cells on a FACScalibur flow cytometer (BD Biosciences, San Diego, CA).

\subsection{Statistical Analysis}

The paired $t$-test was performed using GraphPad Prism version 3.0a software. Differences were considered statistically significant when $\mathrm{p} \leq 0.05$.

\subsection{Immunogenicity studies}

Six to eight-week-old female BALB/c mice were immunized at weeks 0 and 4 with $0.2,2$ or $20 \mu \mathrm{g}$ of plasmid DNA. Eight groups were designated - receiving $\mathrm{pTat}_{\mathrm{wt}} \mathrm{ZA}$,

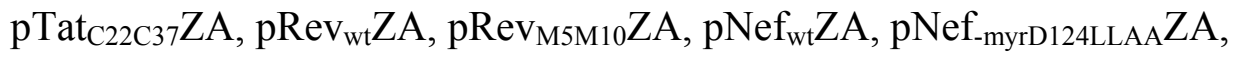
pCTatRevNef $f_{\text {ZA }}$ or plasmid vector alone (naïve group (8)). Groups $1-7$, each consisting of 15 mice, were subdivided into 3 subgroups of 5 animals receiving $0.2,2$ or $20 \mu \mathrm{g}$ dosages of DNA, respectively. The naïve group receiving $20 \mu \mathrm{g}$ pCMVKm2 plasmid consisted of five mice only. The immunizations with individual plasmids and the polygene cassette were conducted simultaneously. DNA was prepared using Endofree plasmid kits (Qiagen) and dissolved in $0.9 \%$ sterile saline solution made up with sterile endotoxin-free water (Sabax). Mice received $50 \mu \mathrm{l}$ of DNA intramuscularly per vaccination site into either posterior thigh muscle using tuberculin syringes (BD Biosciences, San Diego, CA, USA). Animals were killed at week 6 and spleens were removed. Spleen tissue was mascerated between glass slides using serum-free DMEM plus $10 \mathrm{mM}$ HEPES (Invitrogen, Groningen, The Netherlands). Tissue debris was allowed to sediment out in $15 \mathrm{ml}$ centrifuge tubes, cell content was pelleted and cell fractions from all animals within each group were pooled. Erythrocytes were lysed by addition of RBC Lysing Buffer (Sigma) and white cells resuspended in T cell medium 
(1:1 mixture of RPMI 1640 and $\alpha$-MEM, supplemented with 10\% FBS, 1M HEPES, $1 \%$ NEAA, $2 \mathrm{mM}$ L-glutamine (all Invitrogen, Groningen, The Netherlands) and $50 \mu \mathrm{M} 2-$ mercaptoethanol (Sigma)). Splenocytes $\left(10^{6}\right.$ per well) were incubated with antigen (pooled overlapping peptides of HIV-1 subtype C strain Du151 Tat, Rev and Nef at a final concentration of $30 \mu \mathrm{g} / \mathrm{ml}$ ), and $1 \mu \mathrm{g} / \mathrm{ml}$ anti-CD28 (BD Biosciences, San Diego, CA, USA) at $37^{\circ} \mathrm{C}$. Unstimulated control wells contained no antigen and positive control wells contained PHA (1 $\mu \mathrm{g} / \mathrm{ml})$. Brefaldin A (Golgiplug, BD Biosciences, San Diego, CA, USA) was added after $1 \mathrm{~h}$ and cells were incubated for a further $5 \mathrm{~h}$ at $37^{\circ} \mathrm{C}$. Cells were stained for flow cytometry using an intracellular cytokine staining kit (BD Biosciences, San Diego, CA, USA) according to manufacturer's instructions. Briefly, cells were washed, Fc block was added, and then surface stains diluted in staining buffer (anti-CD8 PerCP and anti-CD4 APC) were added. Cells were then fixed, permeabilised and stained intracellularly with anti-CD3 FITC and anti-IFN- $\gamma$ PE diluted in Perm/Wash buffer. Flow cytometry was performed using a four-colour BD FacsCalibur (BD Biosciences, San Diego, CA, USA). CD3 ${ }^{+}$lymphocytes were gated based on FL1 and SSC scatter. $\mathrm{CD}^{+}$lymphocytes were then divided into $\mathrm{CD} 3^{+} \mathrm{CD} 4^{+}$and $\mathrm{CD} 3^{+} \mathrm{CD} 8^{+}$and assessed for IFN- $\gamma$ staining. Antigen-specific responder cells were calculated by subtracting the number of responder cells per 100,000 events in the non-stimulated fraction from those in the antigen-stimulated fraction.

\section{Results}

\subsection{Consensus sequences as vaccine strains}

To select a vaccine strain that will exhibit a minimum genetic distance to currently circulating viruses, amino acid distances were calculated for individual viral isolate sequences from a panel of 14 tat, rev and nef sequence-characterized HIV-1 subtype C isolates versus the remaining 13 isolate sequences. Similarly, the distances between the consensus sequence drawn up from these isolates (designated TV Cons) and the 14 isolate sequences were calculated and the averages of these distances for each regulatory protein are plotted in Fig. 1a. As is distinctly evident for Tat, Rev and Nef individually as well as collectively, the amino acid distance displayed between the consensus sequence 
TV Cons and the 14 isolate sequences was markedly smaller than the distances between any of the individual isolate sequences and those of the remaining isolates. Comparison of genetic distances between the South African consensus TV Cons and four other consensus sequences as well as the sequences from isolates selected for construction of wild-type constructs are plotted in Fig. 1B. For all three regulatory proteins, the smallest amino acid distances were observed between TV Cons and sA Cons, a consensus sequence representing viruses from southern Africa (Botswana and South Africa) and TV Cons and Compl Cons, a consensus sequence constructed from all available subtype $\mathrm{C}$ sequences. The distance between TV Cons and the isolate sequences selected for wildtype constructs on the grounds of being closest to TV Cons were only smaller than that to India Cons, calculated from subtype $\mathrm{C}$ originating from India. These data illustrate a high degree of homology between subtype $\mathrm{C}$ consensus sequences, implying that the use of vaccine constructs based on consensus sequences such as TV Cons may be effectively used to reduce heterogeneity between the vaccine and circulating viruses in a highly diverse epidemic such as subtype $\mathrm{C}$ in sub-Saharan Africa. 


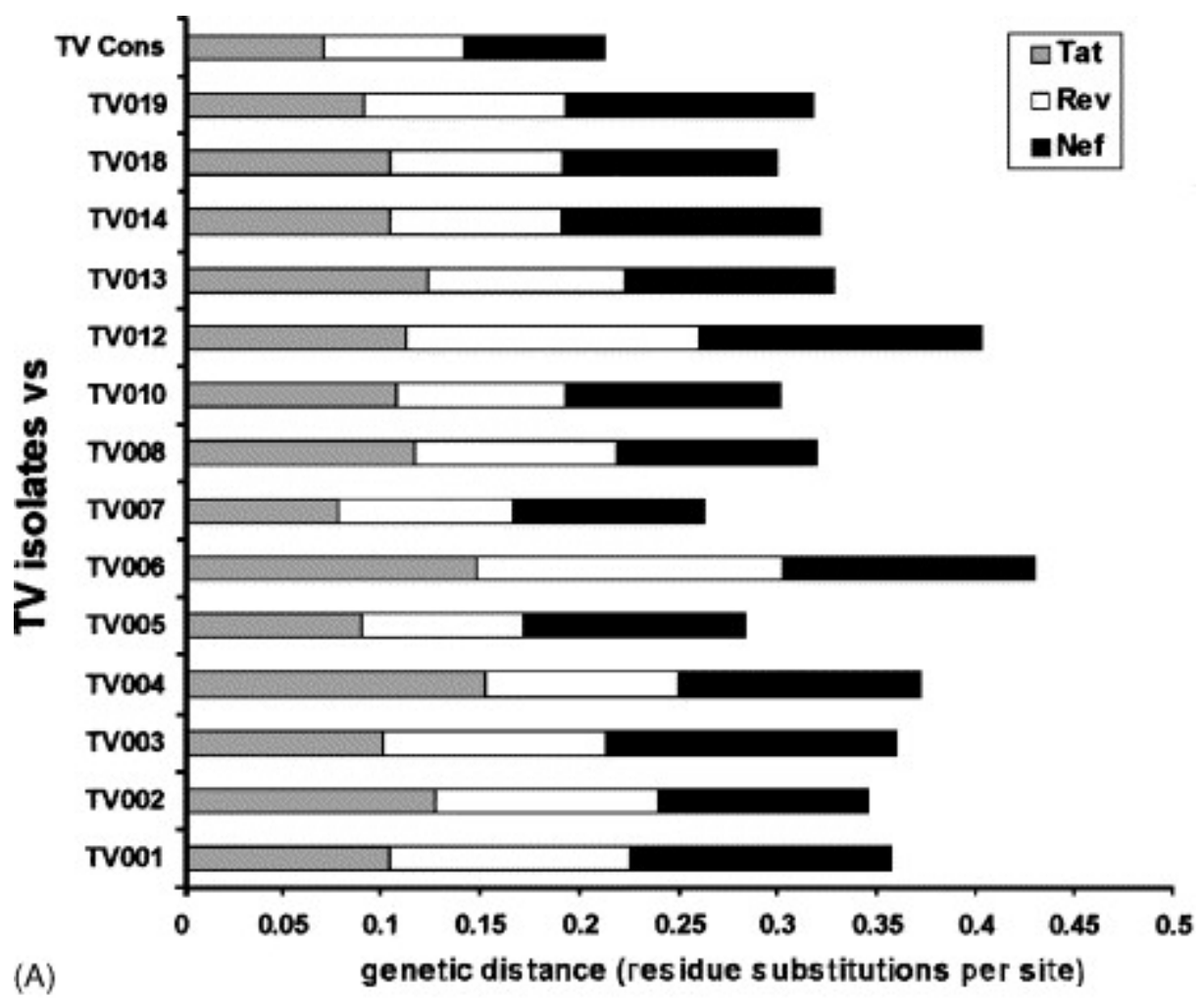

(A)

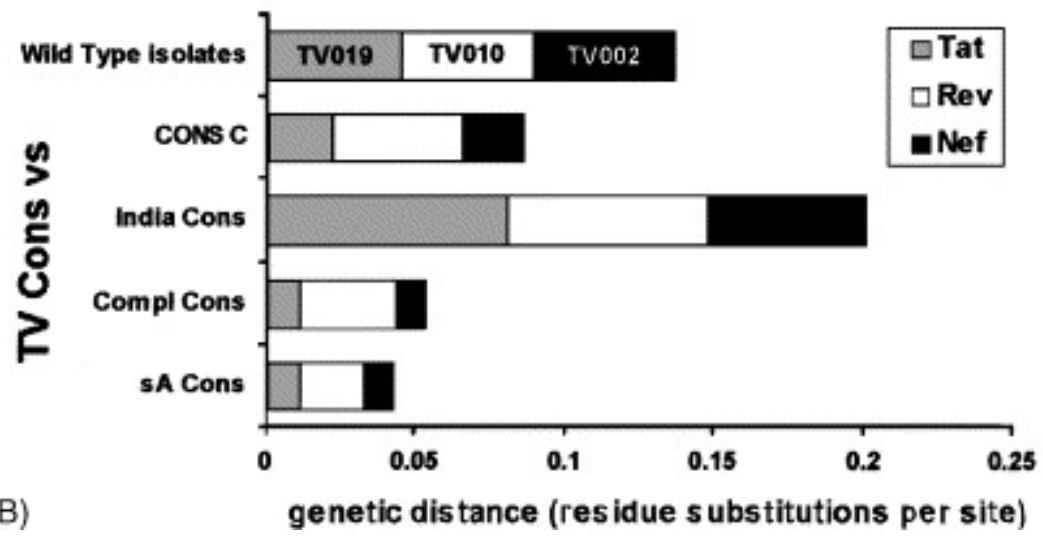

Fig. 1. Amino acid distances calculated with the Kimura distance model. (A) Average distances between the 14 regulatory gene-characterized HIV-1 subtype $\mathrm{C}$ isolates and each individual isolate sequence or the consensus sequence TV Cons plotted as stacked Tat, Rev and Nef bars. (B) Distances calculated between the TV Cons consensus sequence and a panel of subtype $\mathrm{C}$ consensus sequences as well as the Tat, Rev and Nef sequences from those isolates selected for construction of wild-type plasmids (viral isolate indicated). CONS C, subtype C consensus sequence provided by HIV sequence 
database (http://hiv-web.lanl.gov/content/index); India Cons, consensus sequence constructed from subtype $\mathrm{C}$ viruses from India; Compl Cons, consensus constructed from all subtype $\mathrm{C}$ sequences available from HIV sequence database; sA Cons, southern Africa consensus constructed from all subtype $\mathrm{C}$ sequences originating from South Africa and Botswana.

3.2. Construction and in vitro expression of wild-type and codon-optimized tat, rev and nef genes.

The various plasmid constructs with their properties are listed in Table 1. All codonoptimized genes encoded South African consensus (TV Cons) protein sequences of which Tat ${ }_{\mathrm{OPT}}$ and $\mathrm{Nef}_{\mathrm{OPT}}$ were unmutated while a number of mutant proteins were made. The aspartate (D) residue at position 123 that was demonstrated to inactivate subtype B Nef when substituted with a glycine (G) by Liu et al. [37] was present at position 124 in subtype C Nef and this mutation was thus named D124G. Codon-optimization entailed changing the codon usage to that utilized by highly expressed human genes as described previously [44] and resulted in a reduction in AT content of approximately $20 \%$ for the three genes (data not shown).

In vitro expression of all constructs was assessed by SDS-PAGE of 293-cell lysates and immunoblotting with polyclonal Tat, Rev or Nef-specific mouse serum. As this serum was generated by immunization of mice with plasmid DNA, immunoreactivity of the sera with control Tat and Rev proteins (Aids Research and Reference Reagent Program (ARRRP), NIAID, NIH, Maryland, USA) was assessed before use (data not shown). In addition to anti-Nef mouse serum, lysates from Nef-transfected cells were also blotted with a Nef-specific monoclonal antibody (ARRRP).

All subtype $\mathrm{C}$ Tat proteins migrated at a rate corresponding to a molecular weight of approximately $18 \mathrm{kDa}$ and while the codon-optimized plasmids exhibited identical protein expression levels, the wild-type plasmid appeared to yield somewhat lower expression (Fig. 2A). A more notable difference in Rev protein expression levels exhibited by the wild-type and codon-optimized rev plasmids was discernable (Fig. 2B). 
In addition, despite identical lengths in amino acid residues, the mutant Rev protein ( $~$ $14.5 \mathrm{kDa}$ ) migrated more rapidly than the wild-type Rev, which corresponded to $\sim$ $17 \mathrm{kDa}$. A difference in electrophoretic mobility between the wild-type subtype C Rev protein and the subtype B control protein was also seen. Such variations in electrophoretic mobility on SDS-PAGE gels have been reported for Rev proteins with amino acid differences and the alterations in mobility seen here may thus be due to mutations or subtype-specific differences [33], [51] and [53].
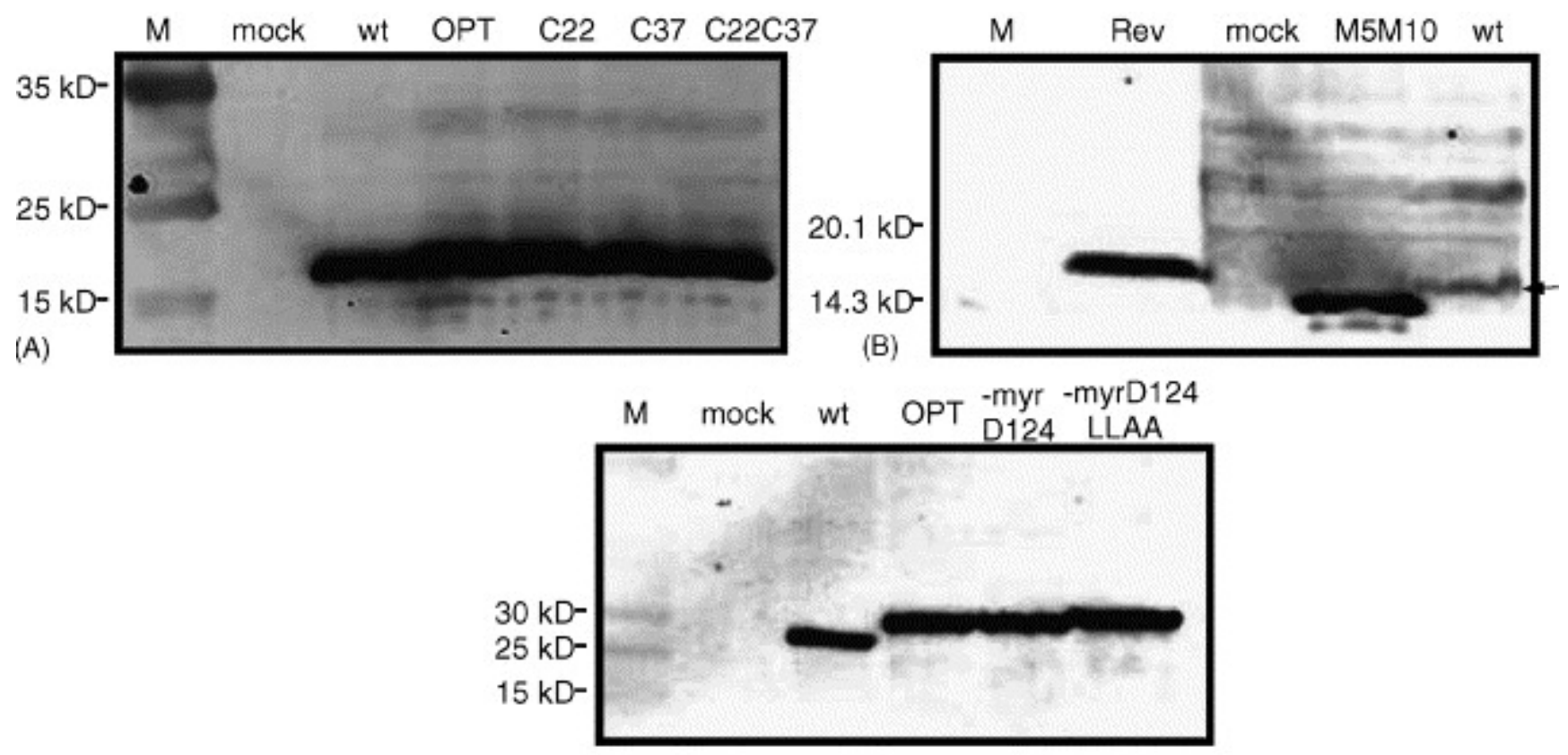

(C)

Fig. 2. Expression of wild-type and codon-optimized Tat, Rev and Nef proteins in transfected 293 cells. Cell-lysates were analyzed by immunoblotting with subtype C Tat and Rev and Nef specific polyclonal mouse serum. Blots representative of multiple transfection experiments (at least three) are shown. (A) Tat-transfected cell lysates. (B) Rev-transfected cell lysates. The arrow indicates the wild-type Rev protein band. The HIV-1 Rev (Wild Type) protein obtained from the ARRRP was used as positive control (Rev). (C) Nef-transfected cell lysates.

In vitro expression levels of the wild-type and various codon-optimized Nef proteins were very similar as demonstrated when immunoblotted with polyclonal anti-Nef mouse 
serum (Fig. 2C) or anti-subtype B Nef monoclonal antibodies (data not shown). The wild-type Nef protein showed increased electrophoretic mobility in comparison to the codon-optimized proteins, which migrated at $\sim 28 \mathrm{kDa}$. Similarly to Rev, this may be due to amino acid differences between the wild-type and optimized proteins. Expression levels between wild-type and codon-optimized nef plasmids were very similar.

\subsection{Identification of non-functional Tat, Rev and Nef-expressing plasmids}

To evaluate the functional activities and identify non-functional regulatory protein immunogens, transient cotransfection experiments were conducted in which key activities of Tat, Rev and Nef were determined.

The transactivation function of the Tat variants was assessed in 293T and HeLa cells by cotransfection with the pLTR-CAT reporter plasmid as previously described [49] and [50]. CAT levels were normalised for transfection efficiency with $\beta$-Galactosidase levels and are expressed as percentage native Tat activity (TatopTZA, set to 100\%) in Fig. 3. A previously described Tat-expressing plasmid (SV40-Tat, [50]) was included as control in 293T cells. No transactivation of LTR-directed CAT expression was recorded in mockor pLTR-CAT only-transfected 293T or HeLa cells. Similar activities were exhibited by the SV40-Tat plasmid in 293T cells and Tat ${ }_{\mathrm{WT}} \mathrm{ZA}$ and TatopT $\mathrm{ZA}$ plasmids in both cell lines. While Tat $_{\mathrm{C}_{22} Z A} \mathrm{Z}$ exhibited an approximate $75 \%$ transactivation activity of native Tat, Tat $_{\mathrm{C} 37} \mathrm{ZA}$ and $\mathrm{Tat}_{\mathrm{C} 22 \mathrm{C} 37} \mathrm{ZA}$ only yielded basal CAT expression. Corresponding results were obtained for $\mathrm{Tat}_{\mathrm{C} 22} \mathrm{ZA}$ and $\mathrm{Tat}_{\mathrm{C22} 237} \mathrm{ZA}$ in single cotransfection experiments in $\mathrm{RD}$ and COS-7 cells (data not shown). 


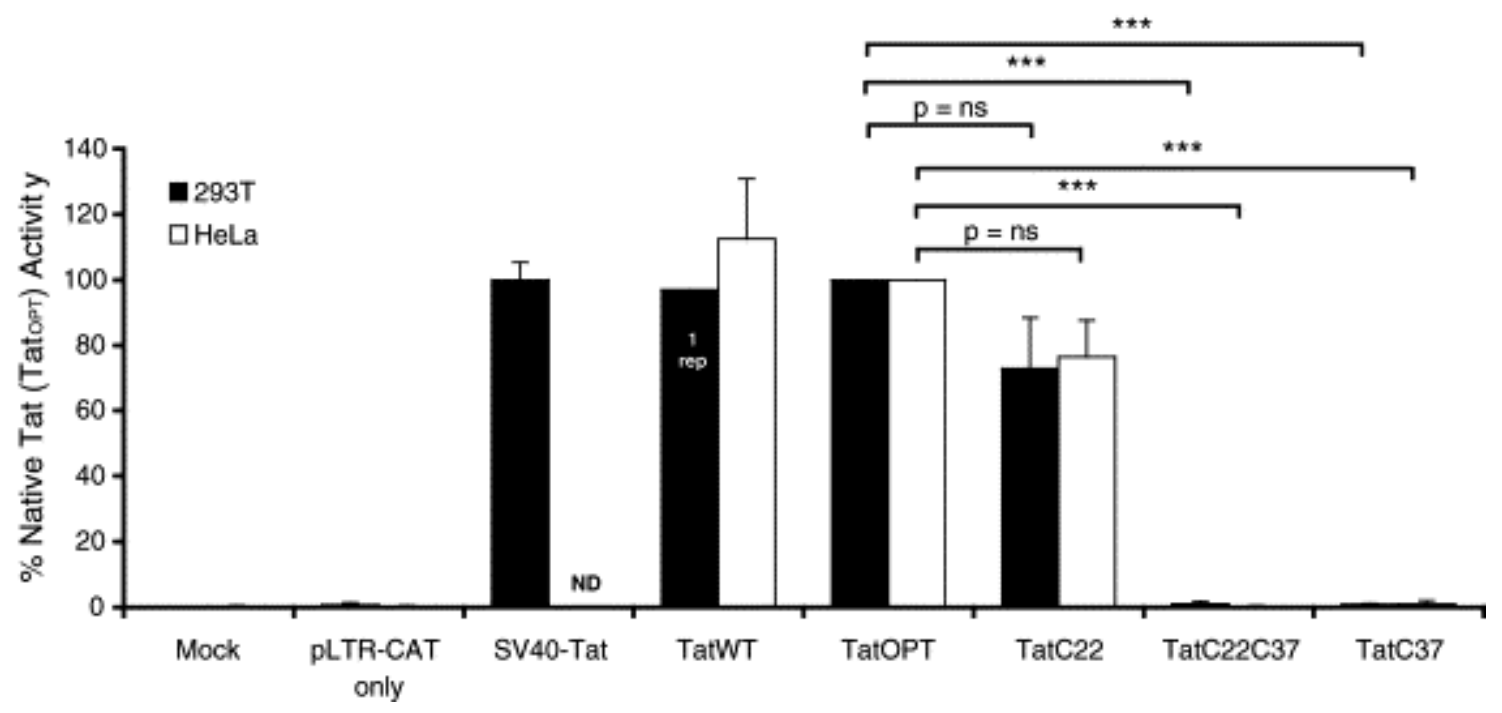

Fig. 3. Functional analysis of Tat mutants in $293 \mathrm{~T}$ and HeLa cells. $\beta$-Galactosidasenormalized CAT levels are expressed as percentage native Tat activity (Tat ${ }_{\mathrm{OPT}} \mathrm{ZA}$, set to 100\%). The subtype B Tat-expressing plasmid pSV40-Tat was used as positive control in 293 T cells. Error bars represent the standard error for three independent experiments. ND, not done; 1 rep, only one experimental repeat done. Statistical analysis was performed using the paired $t$-test. ns $=$ not significant $(p>0.05),{ }^{* * *}$ denotes $p \leq 0.001$.

The functional ability of Rev-expressing plasmids to mediate nuclear export of RREcontaining pDM128 transcripts was performed in 293T cells as described by Hope et al. [51]. The Rev-expressing plasmid pRSV-Rev was utilised as control and CAT expression exhibited by the wild-type $\operatorname{Rev}_{\mathrm{WT}}$ ZA plasmid was set as $100 \%$ activity. All CAT levels were normalised for transfection efficiency with $\beta$-Galactosidase expression levels. While cotransfection with pRSV-Rev and Rev ${ }_{\mathrm{WT}} \mathrm{ZA}$ induced 85- and 25-fold increases in CAT levels respectively, cotransfection with the Rev mutant Rev ${ }_{\mathrm{M} 10}$ ZA yielded CAT levels comparable with basal expression recorded in cells transfected with the reporter plasmid only (Fig. 4). 


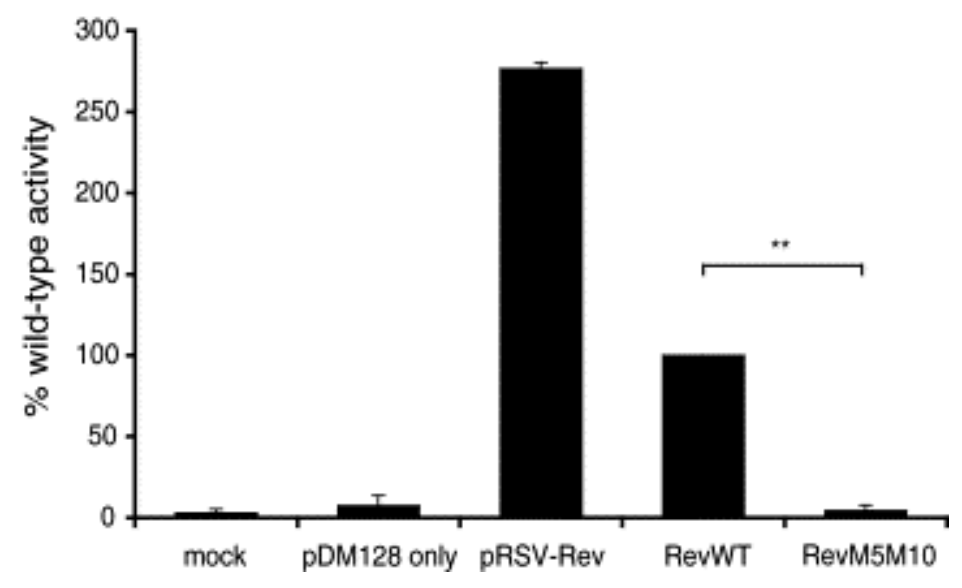

Fig. 4. Functional analysis of Rev mutants in 293 T cells. $\beta$-Galactosidase-normalized CAT levels are expressed as percentage wild-type Rev activity (RevwTZA, set to 100\%). The subtype B Rev expressing pRSV-Rev plasmid [51] was used as positive control. Error bars represent the standard error for three independent experiments. Statistical analysis was performed using the paired $t$-test. ${ }^{* *}$ denotes $p \leq 0.01$.

Ability of Nef variants to modulate downregulation of cell surface CD4 and MHC-I expression was assessed in a transient transfection assay in 293 cells. GFP-expressing cells were identified by flow cytometry and analysed for CD4 and MHC-I expression. Specificity of antibody binding was controlled for with PE or APC conjugated isotypematched control antibodies. Flow cytometric analysis of MHC-I expression on GFPpositive 293 cells transfected with Nef mutants were compared to that on cells transfected with empty control vector (Fig. 5). Comparison of histogram plots distinctly revealed Nef-mediated downregulation of MHC-I expression on $\mathrm{Nef}_{\mathrm{WT}} \mathrm{ZA}$ and $\mathrm{Nef}_{\mathrm{OPT}} \mathrm{ZA}-$ transfected cells. This data is demonstrated more clearly when mean APC-fluorescence is represented in graphical format in Fig. 6, showing that cells transfected with the codonoptimized Nef $\mathrm{OPT}_{\mathrm{Z}} \mathrm{ZA}$ plasmid exhibited the most MHC-I downregulation (MHC-I expression below 80\% normal). MHC-I expression was downregulated to a level below $90 \%$ in $\mathrm{Nef}_{\mathrm{WT}} \mathrm{ZA}$-transfected cells, while this activity was completely inhibited in both Nef mutants. CD4 expression levels, recorded as mean PE-fluorescence on GFP-positive cells, are expressed as percentage expression on cells transfected with empty pCMVKm2 vector (set to $100 \%$ ) in Fig. 6. Similarly to MHC-I expression, CD4 expression was most 
severely downregulated in $\mathrm{Nef}_{\mathrm{OPT}} \mathrm{ZA}$-transfected cells (less than 50\%) while expression on $\mathrm{Nef}_{\mathrm{WT}} \mathrm{ZA}$-transfected cell surfaces was downregulated to approximately $60 \%$ of

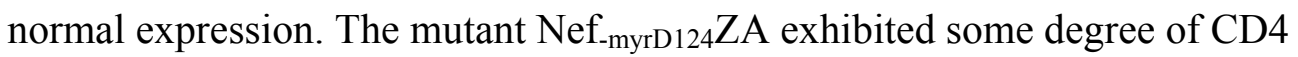
downregulation activity as represented by CD4 surface expression of $\sim 80 \%$. This function was completely abrogated for mutant $\mathrm{Nef}_{\text {-myrD124LLAA }} \mathrm{ZA}$. It should be noted that an intrinsic experimental limitation exists in cotransfection experiments such as these by the fact that cells need to take up all three plasmids.
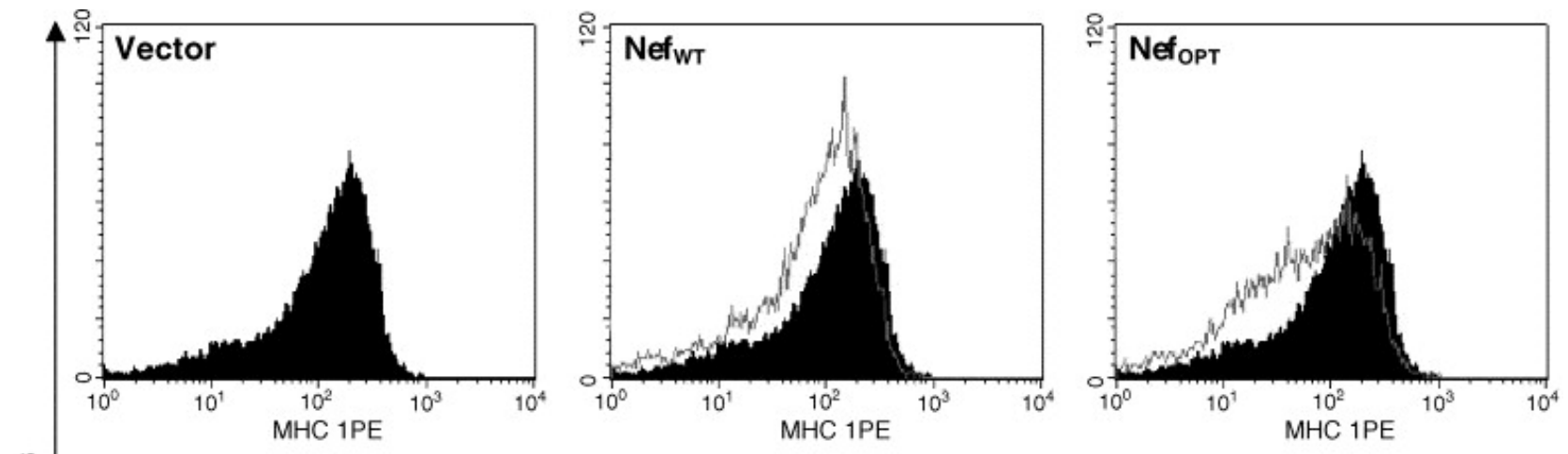

옳
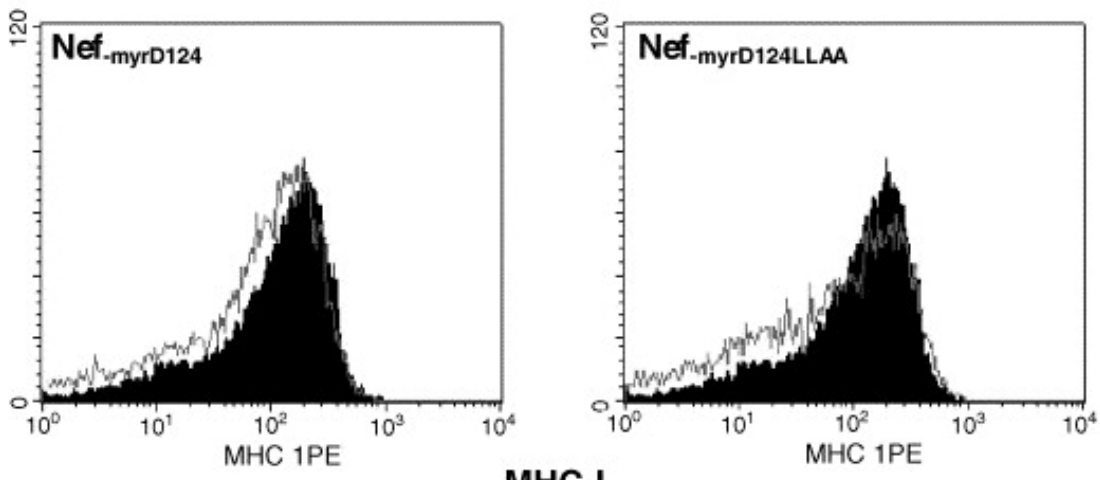

MHC-I

Fig. 5. Flow cytometric analysis of MHC-I expression on the surface of Nef-transfected 293 cells. Histogram overlays of Nef-transfected cells (outlined) and cells transfected with empty control vector (black fill) showing MHC-I fluorescence recorded by twocolour flow cytometry on GFP-positive cells. 


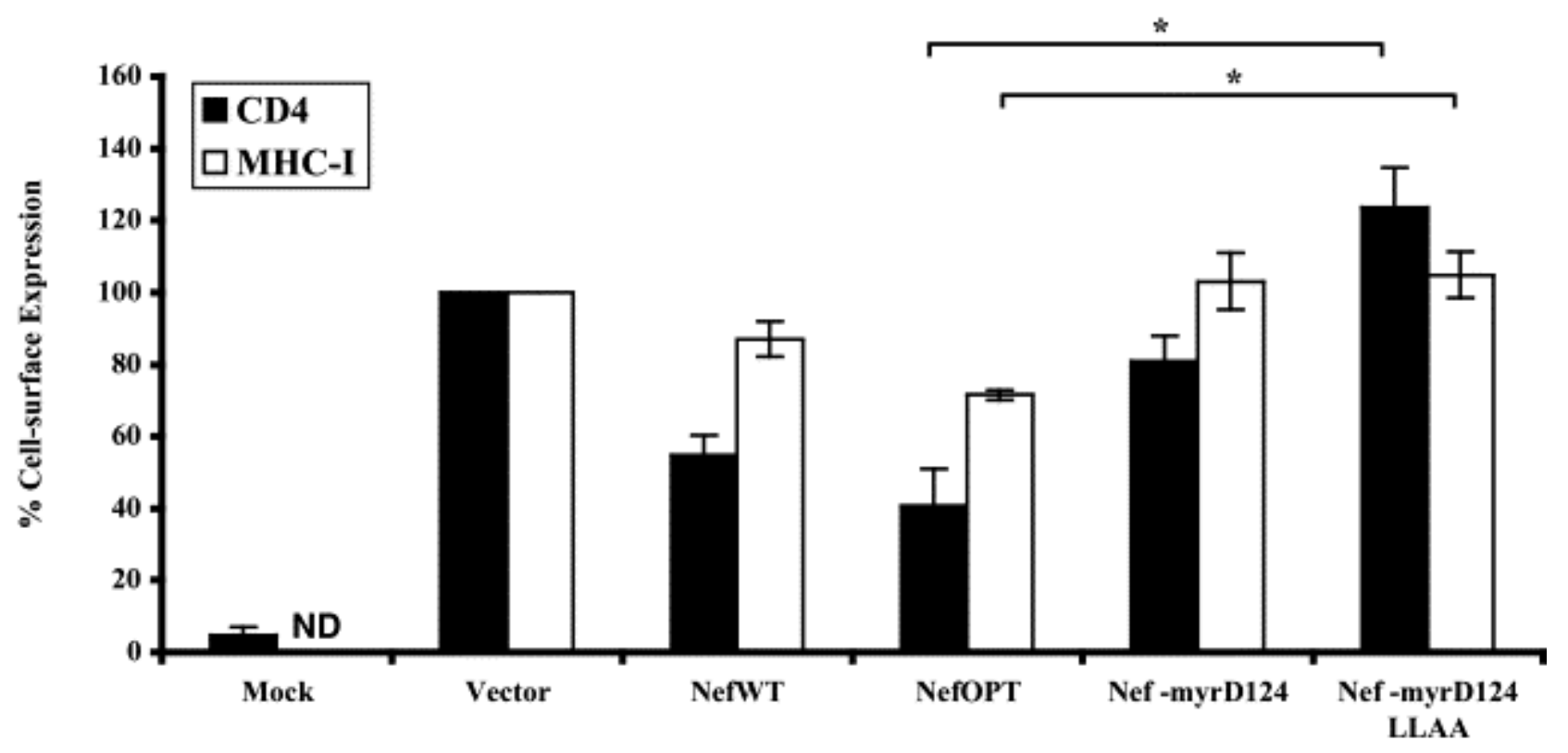

Fig. 6. Analysis of Nef-mediated CD4 and MHC-I downregulation. 293-cell surface expression of CD4 and MHC-I was recorded as mean fluorescence intensity by flow cytometry on GFP-positive cells and shown as percent expression of vector-transfected cells (set to 100\%). Error bars represent the standard error for three independent experiments. ND, not determined. Statistical analysis was performed using the paired $t$ test. ${ }^{*}$ denotes $p \leq 0.05$.

3.4. Assembly and expression of a non-functional TatRevNef DNA vaccine cassette

While the results of Tat and Nef functionality assays were not as expected, plasmid constructs Tat ${ }_{\mathrm{C} 37} \mathrm{ZA}$ and $\mathrm{Tat}_{\mathrm{C} 22 \mathrm{C} 37} \mathrm{ZA}, \mathrm{Rev}_{\mathrm{M} 5 \mathrm{M} 10} \mathrm{ZA}$ and Nef-myrD124LLAA ZA were demonstrated to be functionally inactive. Based on these results, the reading frames of plasmid constructs $\operatorname{Tat}_{\mathrm{C} 22 \mathrm{C} 37} \mathrm{ZA}, \mathrm{Rev}_{\mathrm{M} 5 \mathrm{M} 10} \mathrm{ZA}$ and $\mathrm{Nef}_{\text {-myrD124LLAA }} \mathrm{ZA}$ were fused to form a TatRevNef polygene cassette (pCTatRevNef $\mathrm{ZA}_{\mathrm{A}}$ ). In vitro expression of the TatRevNef polyprotein in 293 cells was assessed by immunoblot analysis and yielded a $50 \mathrm{kDa}$ protein band that was immunoreactive to anti-Tat (Fig. 7), Rev and Nef mouse serum (data not shown). 


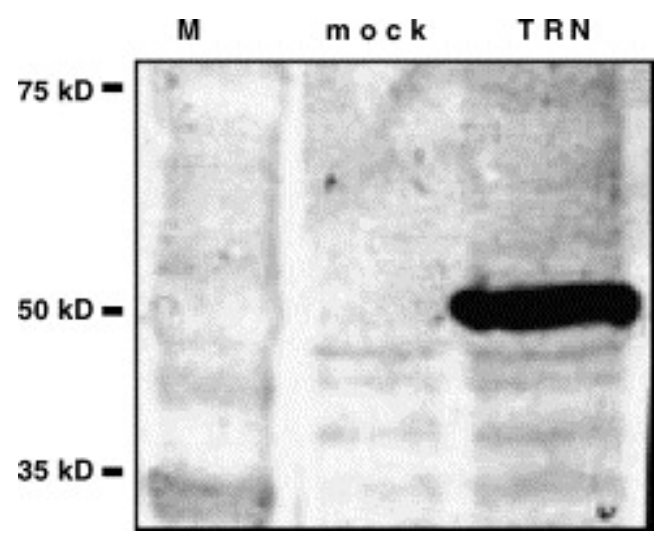

Fig. 7. Expression of the codon-optimized pCTatRevNef $f_{\text {ZA }}$ polygene (TRN) cassette in transfected 293 cells. Lysates from 293 cells were immunoblotted with anti-Tat mouse serum.

\subsection{Immunogenicity assessment}

Immunogenicity was assessed by flow cytometric analysis of intracellular interferon gamma (IFN- $\gamma$ ) production in $\mathrm{CD}^{+} \mathrm{T}$ lymphocyte populations. The data are summarized in Fig. 8. No antigen-specific responses were observed in the control groups.

Immunisation with wild-type plasmid DNA stimulated expansion of antigen-specific $\mathrm{CD}^{+}$splenocytes. All three wild-type constructs elicited good antigen-specific $\mathrm{CD}^{+} \mathrm{T}$ cell responses. Responses were observed in all groups for each of the three HIV proteins immunised with $20 \mu \mathrm{g}$ and $2 \mu \mathrm{g}$ plasmid DNA and responses to the lowest plasmid DNA dose $(0.2 \mu \mathrm{g})$ were seen for all constructs but the single wild-type and codon-optimized mutant Rev. All $\mathrm{CD}^{+}$responses titrated out at lower dosages. Vaccination with the mutant Tat construct resulted in markedly higher responses compared with the wild-type Tat, however this was not the case for Rev and Nef responses, which showed no major differences in responder frequencies. Vaccination with the mutated TatRevNef cassette elicited similar frequencies of $\mathrm{CD}^{+}$responses to Rev and Nef while Tat was less immunogenic in the polygene cassette than when tested as a single mutated gene construct. 

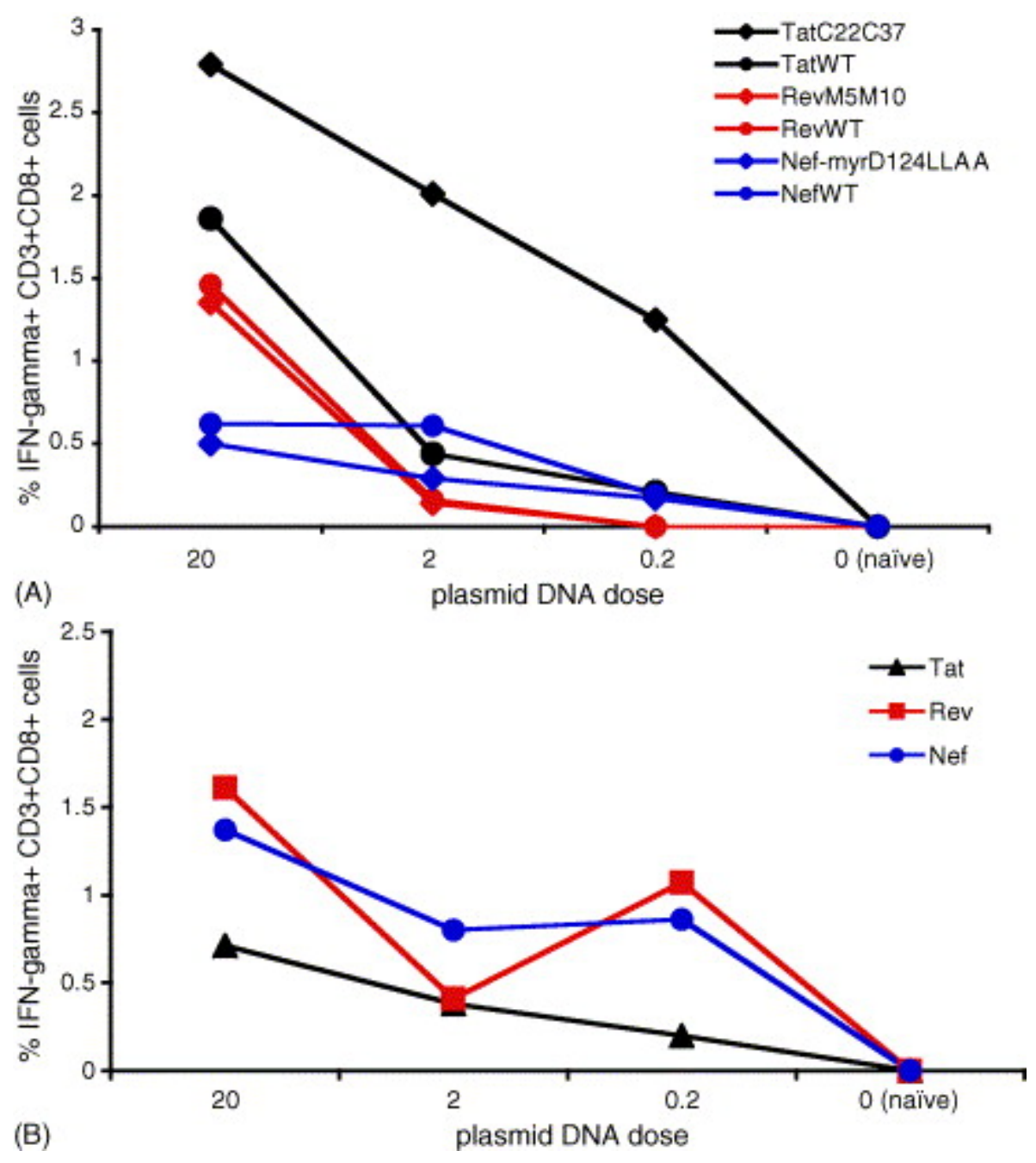

Fig. 8. Frequencies of Tat, Rev and/or Nef-specific $\mathrm{CD} 8^{+}$splenocytes expressing IFN- $\gamma$ in BALB/c mice immunized with wild-type or codon-optimized mutated plasmid DNA constructs. Cells were restimulated with antigen-matched pooled peptides as indicated prior to flow cytometric analysis. The percentage IFN- $\gamma$-positive cells in mice immunized with single-gene constructs (A) and the polygene pCTatRevNef $\mathrm{ZA}_{\mathrm{Z}}$ cassette (B) are plotted for each immunogen.

\section{Discussion}

Sequence analysis of the subtype $\mathrm{C}$ consensus sequence that was used to construct the Tat, Rev and Nef immunogens revealed a markedly smaller genetic distance between the 
consensus and a panel of viral isolate sequences compared to any individual isolate and the panel of viral isolate sequences. This corresponds with previous reports that demonstrated the use of a consensus sequence as vaccine strain to reduce genetic variability between such a vaccine and circulating viruses [54] and [55]. Thus, a less heterologous vaccine may have direct implications on specificity of the vaccine-induced immune responses and immunoreactivity with viruses in an epidemic of high intrasubtype diversity such as subtype $\mathrm{C}$ in southern Africa.

Numerous studies have defined T-cell epitopes with known HLA restriction in virtually all HIV proteins [56]. Although most of these studies were restricted to individuals infected with subtype B viruses, cross-clade sequence conservation and some identification of such epitopes in subtype $\mathrm{C}$ sequences makes it possible to map known epitopes onto the vaccine sequences described in this study. Mapping Tat, Rev and Nefspecific epitopes onto the consensus sequences revealed subtype-specific single residue substitutions in Tat and Rev that disrupted most known subtype B epitopes (data not shown), making immunogenicity predictions challenging. These findings illustrate the need for epitope mapping in the regulatory genes of non-B subtypes. However, many Nef-specific epitopes could be identified in the consensus subtype $\mathrm{C}$ Nef sequence, with especially high frequencies of CTL-epitopes in the conserved domains, suggesting Nefresponses to be potentially cross-reactive. These analyses also confirmed that the use of selected single or double mutations to inactivate these proteins do not disrupt epitope sequences [57]. However, the rationale of conserving Nef epitopes by incorporating the G2A and LL174AA mutations was utilized for another Nef vaccine and resulted in decreased immunogenicity in mice [58], suggesting that the efficacy of this approach will have to be investigated further.

Analysis of the functional activity of Tat revealed that, unlike numerous previous studies demonstrating the inactivity of Tat with a C22G mutation [28], [29], [49] and [59], the subtype C TatC22 was able to activate LTR-directed CAT transcription. The reason for this finding is not clear. Because the assays used in this study were done as those described by Kuppuswamy et al. [49], who also used the same reporter plasmid and performed the transactivation assays in HeLa cells, the possibility of different 
methodology can be excluded. The importance of cysteine residue conservation at position 22 in Tat is well established. Cys 22 is highly conserved among HIV-1 and also a large number of HIV-2 and SIV viruses [60] and with the exception of our work, every previously published experiment has shown that mutation of this residue abrogates transactivation [28], [29], [30], [32], [49], [59], [61], [62] and [63]. When dissected, only two disparities between these previous experiments and the Tat transactivation work described in this study can be recognized, and both implicate the Tat protein. Firstly, to our knowledge, all studies that concern functional dissection, mutation or structural analysis of Tat have been conducted on proteins encoded by HIV-1 subtype B genomes, most of which were molecular clones derived from the same laboratory strain (LAI, IIIB, $A R V)$. The fact that the Tat proteins analysed here are from subtype $C$ viruses may be accompanied by suspicions that the intrinsic structures and functions of Tat proteins from different HIV subtypes can differ. Indeed, it is well known that the long terminal repeat as well as a number of proteins including Rev, Vpu and the C-terminal of Pol are distinctly different in subtype $\mathrm{C}$ viruses when compared to other subtypes [64], [65], [66] and [67]. Moreover, while the third variable loop in the Env protein is highly variable in virtually all subtypes, this region was shown to be considerably more conserved in subtype $\mathrm{C}$ viruses [68]. Sequence characterization of the subtype $\mathrm{C}$ isolates on which our Tat, Rev and Nef vaccine candidates were based confirmed the presence of these Cspecific signatures in the LTR, Vpu and Rev regions [41] and [42] as well as the conserved nature of the envelope V3 sequences [40]. It would thus not be unreasonable to speculate about the unexplored subtype factor possibly playing a role in a different structure or function of Tat. Notably, in similar studies, when the functionality of the subtype B Tat protein from isolate SF162, which carried the C22 mutation, was determined in $293 \mathrm{~T}$ cells the results were identical to the subtype C Tat data in this study. Furthermore, mutation of the C37 residue or mutation of both C22 and C37 in the SF162 Tat brought about abrogation of transactivation activity (zur Megede, unpublished data). These results point to the equally important possibility that strain-specific variation, rather than subtype-specific variation may affect protein functionality and thus, should be considered for HIV vaccine development. A second distinction between the work completed in this study and again, to our knowledge, all previous studies describing the 
Tat22 mutant is the factor of protein length. Most studies investigating the function and structure of Tat22 (and many other studies) were conducted on the 86 amino acid Tat protein from the early laboratory strains that contained a premature truncation in tat exon 2 , and not the full-length 101 amino acid Tat that is seen predominantly in wild-type viruses [60]. Yet, early studies showed that the second exon was expendable for transactivation activity [69]. A number of recent studies however, have demonstrated that the second exon, which encompasses 29 amino acids in most strains, enhances viral replication [70] and pathogenesis [71] of HIV-1. The possibility exists that the full length Tat proteins (subtype C consensus and subtype B SF162) used in this study may not have been inactivated for transactivation activity by mutation of $\mathrm{C} 22$ because of a counteracting function of the C-terminal second exon. Interestingly, a Tat mutant (Y26A), which was defective for transactivation activity and viral replication, regained activity when a second-site suppressor mutation (Y47N) was acquired [72]. Thus, we hypothesise that subtype $\mathrm{C}$ viruses may have acquired a mechanism whereby single point mutations involving specific critical cysteine residues may be insufficient to abrogate transactivation activity of Tat. These data certainly provoke consideration of such concepts, but these questions will remain unanswered until they are experimentally defined.

As expected, the mutated consensus Rev construct displayed no functional activity. Although, no unmutated consensus Rev construct was tested in this study to confirm the abrogation of functionality though mutation of the specific residues, such a consensus Rev protein could be expected to be functionally active as its amino acid sequence reveals no abnormal residue combinations or substitutions in the functional domains [41]. The relatively lower increase in reporter gene expression (25-fold) by C-clade Rev compared to the published 85-fold increase by B-clade Rev [25] is probably as a result of the considerably lower expression level of the wild-type C-clade Rev.

Similarly to the Tat ${ }_{\mathrm{C} 22}$ mutant, mutation of the subtype C Nef myristoylation signal (G2A) and a conserved aspartate at position 124, which was previously shown to be critical for oligomerization, downregulation of CD4 and MHC-I and decreasing viral infectivity [37], was not sufficient to completely abrogate CD4 downregulation activity. 
The finding that the additional substitution of the dileucine motif at position 165 completely disrupts CD4 downregulation confirms the critical importance of this motif for the CD4-downregulation activity of Nef [38] and [73]. The reason for this discrepancy in functional activity of an unmyristoylated subtype $\mathrm{C}$ Nef carrying the D124G mutation, with previous data that demonstrated such mutations to sufficiently inactivate subtype B Nef, is unclear. As we used the same methodologies that have been used to demonstrate these findings for subtype B Nef [52] and [57], methodology can be eliminated as possible cause. Again, the major differences between our Nef constructs and those studied previously are the subtype and viral strain. These discrepant results makes it reasonable to express concern about the belief that inactivation of such regulatory proteins through site-specific mutations is conserved across all viral strains and subtypes.

The codon-optimization of the different reading frames had variable effects on the expression rates of the proteins. Besides mRNA stability, which is the major factor influenced by codon-optimization, many factors such as protein stability and length, nucleotide and amino acid composition contribute towards protein expression rates and half-lives. The mechanisms behind these differing influences on expression require further investigation.

Vaccination of mice with plasmid DNA encoding either wild-type or codon-optimized, mutated, consensus Tat, Rev and Nef proteins was performed to assess the potential immunogenicity of these constructs. Immunoblotted Tat, Rev and Nef proteins were immunoreactive with serum from immunized CB6F1 mice and antigen-specific $\mathrm{T}$ lymphocyte responses were generated in BALB/c mice. These results demonstrate successful expression and antigen presentation of these plasmid constructs in the murine model. Codon-optimization of these genes appeared to have made no marked difference in the immunogenicity of the single-gene Rev and Nef constructs. However, there was a markedly increased $\mathrm{T}$ lymphocyte response in mice that received the codon-optimized Tat compared to those that received the wild-type. Notably, the use of consensus protein sequences carrying the respective inactivating mutations did not significantly diminish the immunogenicity of the codon-optimized proteins. 
It should be noted that the peptide pools used for splenocyte stimulation in the intracellular cytokine assays were derived from HIV-1 subtype C strain Du151 (Accession no. AY043173) and were thus not autologous. The mean percentage of amino acid differences between the Tat, Rev and Nef proteins of strain Du151 and those used as immunogens in this study is $10.1 \%$ (range $7.4-12.8 \%$ ). Due to the potential residue differences in BALB/c-restricted CTL epitopes contained in the immunogens used in the vaccinations and those used in the in vitro lymphocyte stimulation assays, antigenspecific responses may have been underestimated. Nevertheless, the vaccine components described in this study were found to be immunogenic and responses diminished with decreasing plasmid DNA dose, suggesting dose-dependent responses.

HIV-1 subtype $\mathrm{C}$ has attained a global distribution and is currently responsible for over half of all HIV infections worldwide [1] and [2]. While modern vaccine strategies have become multifaceted to aim at elicitation of broad and durable humoral and cellular immune responses, such new strategies often incorporate Tat, Rev and Nef as vaccine immunogens. However, to address safety issues raised by the inclusion of these gene products, such efforts have relied on clear data illustrating the functional inactivity of these gene products. The recent interest in developing and testing new generation vaccines has commonly seen the simple application of vaccine design concepts that were proven on specific strains to vaccines based on other viral strain or even subtype sequences. In this study we induced mutations in subtype C Tat, Rev and Nef constructs that were previously repeatedly shown to render the corresponding subtype B regulatory proteins inactive. Functional analysis of these constructs revealed some discrepancies in functional inactivities between our subtype $\mathrm{C}$ Tat, Rev and Nef constructs and previously described subtype B immunogens. This raises concerns about the blind application of such vaccine design concepts to strain-unrelated vaccine components.

This study thus served at identifying HIV-1 subtype C-specific mutated Tat, Rev and Nef constructs that were shown to be devoid of undesired functional activities, were sufficiently immunogenic and may thus be utilized as AIDS vaccine components. In the light of striving for more broadly reactive HIV-1 vaccines, the single-gene or polygene 
cassette constructs may serve to increase antigenic breadth of an HIV-1 subtype C vaccine.

\section{Acknowledgements}

TJS and JzM contributed equally to this work. We thank Annette Laten for excellent work with DNA sequencing. Gillis Otten at Chiron Corporation for the hCD4-encoding plasmid, Hanna Veenstra at the Dept. Medical Biochemistry, Stellenbosch University for the 293T cell line, Lester Davids at the Liver Research Centre, University of Cape Town, RSA for the pEGFP-N1 vector and Thomas Hope at the Chicago College of Medicine, Illinois, for the pDM128 and pRSV-Rev plasmids. The following reagents were obtained through the AIDS Research and Reference Reagent Program, NIAID, NIH: HIV-1 Tat protein from Dr. John Brady, HIV-1 Rev (Wild Type) from Dr. David Rekosh, Dr. Marie-Louise Hammarskjöld and Mr. Michael Orsini, HIV-1 $1_{\text {JR-CSF }}$ Nef monoclonal antibodies from Dr. Kai Krohn and Dr. Vladimir Ovod. This work was supported by grants from the South African AIDS Vaccine Initiative (SAAVI), the Poliomyelitis Research Foundation and USPHS NIH-NIAID Contract No. N01-AI-05396.

\section{References}

[1] UNAIDS. (December 2002). Report on the global HIV/AIDS epidemic. UNAIDS, Geneva, Switzerland.

[2] J. Esparza and N. Bhamarapravati, Lancet (2000), p. 355.

[3] S. Osmanov, C. Pattou, N. Walker, B.J. Schwardlander and J. Esparza, Acquir Immune Defic Syndr (2002), p. 29. 
[4] P. Borrow, H. Lewicki, B.H. Hahn, G.M. Shaw and M.B. Oldstone, J Virol 68 (1994), pp. 6103-6110.

[5] S.A. Kalams, S.P. Buchbinder, E.S. Rosenberg, J.M. Billingsley, D.S. Colbert and N.G. Jones et al., J Virol 73 (1999), pp. 6715-6720.

[6] M.R. Klein, C.A. van Baalen, A.M. Holwerda, G. Kerkhof Sr., R.J. Bende and I.P. Keet et al., J Exp Med 181 (1995), pp. 1365-1372.

[7] P.A. Moss, S.L. Rowland-Jones, P.M. Frodsham, S. McAdam, P. Giangrande and A.J. McMichael et al., Proc Natl Acad Sci USA 92 (1995), pp. 5773-5777.

[8] L. Musey, J. Hughes, T. Schacker, T. Shea, L. Corey and M.J. McElrath, N Engl J Med 337 (1997), pp. 1267-1274.

[9] G.S. Ogg, X. Jin, S. Bonhoeffer, P.R. Dunbar, M.A. Nowak and S. Monard et al., Science 279 (1998), pp. 2103-2106.

[10] R. Kaul, F.A. Plummer, J. Kimani, T. Dong, P. Kiama and T. Rostron et al., J Immunol 164 (2000), pp. 1602-1611.

[11] S.L. Rowland-Jones, T. Dong, K.R. Fowke, J. Kimani, P. Krausa and H. Newell et al., J Clin Invest 102 (1998), pp. 1758-1765.

[12] S. Rowland-Jones, J. Sutton, K. Ariyoshi, T. Dong, F. Gotch and S. McAdam et al., Nat Med 1 (1995), pp. 59-64.

[13] D.A. Price, P.J. Goulder, P. Klenerman, A.K. Sewell, P.J. Easterbrook and M. Troop et al., Proc Natl Acad Sci USA 94 (1997), pp. 1890-1895.

[14] C.A. van Baalen, O. Pontesilli, R.C. Huisman, A.M. Geretti, M.R. Klein and F. de Wolf et al., J Gen Virol 78 (1997), pp. 1913-1918.

[15] M. Robert-Guroff, M. Popovic, S. Gartner, P. Markham, R.C. Gallo and M.S. Reitz, J Virol 64 (1990), pp. 3391-3398. 
[16] P. Mooij and J.L. Heeney, Vaccine 20 (2001), pp. 304-321.

[17] C. Moureau, M. Moynier, V. Kavsan, L. Montagnier and E. Bahraoui, Vaccine 18 (1999), pp. 333-341.

[18] A. Cafaro, A. Caputo, C. Fracasso, M.T. Maggiorella, D. Goletti and S. Baroncelli et al., Nat Med 5 (1999), pp. 643-650.

[19] A. Cafaro, F. Titti, C. Fracasso, M.T. Maggiorella, S. Baroncelli and A. Caputo et al., Vaccine 19 (2001), pp. 2862-2877.

[20] A.D. Osterhaus, C.A. van Baalen, R.A. Gruters, M. Schutten, C.H. Siebelink and E.G. Hulskotte et al., Vaccine 17 (1999), pp. 2713-2714.

[21] P. Secchiero, D. Zella, S. Capitani, R.C. Gallo and G. Zauli, J Immunol 162 (1999), pp. 2427-2431.

[22] J.F. Zagury, A. Sill, W. Blattner, A. Lachgar, H. Le Buanec and M. Richardson et al., J Hum Virol 1 (1998), pp. 282-292.

[23] T.J. Hope, Arch Biochem Biophys 365 (1999), pp. 186-191.

[24] M.D. Miller, M.T. Warmerdam, I. Gaston, W.C. Greene and M.B. Feinberg, J Exp Med 179 (1994), pp. 101-113.

[25] J.V. Garcia and A.D. Miller, Nature 350 (1991), pp. 508-511.

[26] O. Schwartz, V. Marechal, S. Le Gall, F. Lemonnier and J.M. Heard, Nat Med 2 (1996), pp. 338-342.

[27] C.M. Steffens and T.J. Hope, AIDS (2001) (15 Suppl), pp. S21-S26.

[28] J.A. Garcia, D. Harrich, L. Pearson, R. Mitsuyasu and R.B. Gaynor, EMBO J 7 (1988), pp. 3143-3147. 
[29] S. Ruben, A. Perkins, R. Purcell, K. Joung, R. Sia and R. Burghoff et al., J Virol 63 (1989), pp. 1-8.

[30] M. Betti, R. Voltan, M. Marchisio, I. Mantovani, C. Boarini and F. Nappi et al., Vaccine 19 (2001), pp. 3408-3419.

[31] S.A. Calarota, A.C. Leandersson, G. Bratt, J. Hinkula, D.M. Klinman and K.J. Weinhold et al., J Immunol 163 (1999), pp. 2330-2338.

[32] E. Caselli, M. Betti, M.P. Grossi, P.G. Balboni, C. Rossi and C. Boarini et al., J Immunol 162 (1999), pp. 5631-5638.

[33] M.H. Malim, S. Bohnlein, J. Hauber and B.R. Cullen, Cell 58 (1989), pp. 205-214.

[34] U. Ranga, C. Woffendin, S. Verma, L. Xu, C.H. June and D.K. Bishop et al., Proc Natl Acad Sci USA 95 (1998), pp. 1201-1206.

[35] C. Woffendin, U. Ranga, Z. Yang, L. Xu and G.J. Nabel, Proc Natl Acad Sci USA 93 (1996), pp. 2889-2894.

[36] T.M. Niederman, W.R. Hastings and L. Ratner, Virology 197 (1993), pp. 420-425. [37] L.X. Liu, N. Heveker, O.T. Fackler, S. Arold, S. Le Gall and K. Janvier et al., J Virol 74 (2000), pp. 5310-5319.

[38] P.A. Bresnahan, W. Yonemoto, S. Ferrell, D. Williams-Herman, R. Geleziunas and W.C. Greene, Curr Biol 8 (1998), pp. 1235-1238.

[39] M. Greenberg, L. DeTulleo, I. Rapoport, J. Skowronski and T. Kirchhausen, Curr Biol 8 (1998), pp. 1239-1242.

[40] S. Engelbrecht, T. de Villiers, C.C. Sampson, J. zur Megede, S.W. Barnett and E.J. van Rensburg, AIDS Res Hum Retrovir 17 (2001), pp. 1533-1547. 
[41] T.J. Scriba, T. de Villiers, F.K. Treurnicht, J. zur Megede, S.W. Barnett and S.

Engelbrecht et al., AIDS Res Hum Retrovir 18 (2002), pp. 149-159.

[42] T.J. Scriba, F.K. Treurnicht, M. Zeier, S. Engelbrecht and E.J. van Rensburg, AIDS Res Hum Retrovir 17 (2001), pp. 775-781.

[43] F.K. Treurnicht, T.L. Smith, S. Engelbrecht, M. Claassen, B.A. Robson and M. Zeier et al., J Med Virol 68 (2002), pp. 141-146.

[44] J. zur Megede, S. Engelbrecht, T. de Oliveira, S. Cassol, T.J. Scriba and E.J. van Rensburg et al., AIDS Res Hum Retrovir 18 (2002), pp. 1327-1332.

[45] M. Kimura, J. Mol. E vol. 16 (1980), pp. 111-120.

[46] J. zur Megede, M.C. Chen, B. Doe, M. Schaefer, C.E. Greer and M. Selby et al., J Virol 74 (2000), pp. 2628-2635.

[47] A.V. Kochetov, I.V. Ischenko, D.G. Vorobiev, A.E. Kel, V.N. Babenko and L.L. Kisselev et al., FEBS Lett 440 (1998), pp. 351-355.

[48] M.M. Kozak, J Biol Chem 266 (1991), pp. 19867-19870.

[49] M. Kuppuswamy, T. Subramanian, A. Srinivasan and G. Chinnadurai, Nucleic Acids Res 17 (1989), pp. 3551-3561.

[50] B.M. Peterlin, P.A. Luciw, P.J. Barr and M.D. Walker, Proc Natl Acad Sci USA 83 (1986), pp. 9734-9738.

[51] T.J. Hope, X.J. Huang, D. McDonald and T.G. Parslow, Proc Natl Acad Sci USA 87 (1990), pp. 7787-7791.

[52] M.A. Goldsmith, M.T. Warmerdam, R.E. Atchison, M.D. Miller and W.C. Greene, J Virol 69 (1995), pp. 4112-4121. 
[53] M.H. Malim, D.F. McCarn, L.S. Tiley and B.R. Cullen, J Virol 65 (1991), pp. 42484254.

[54] Brander C, Goulder PJR, Human Retroviruses and AIDS Los Alamos National Laboratory, Los Alamos, NM. 2001.

[55] V. Novitsky, U.R. Smith, P. Gilbert, M.F. McLane, P. Chigwedere and C.

Williamson et al., J Virol 76 (2002), pp. 5435-5451.

[56] B. Korber, C. Brander, B. Haynes, R. Koup, C.L. Kuiken and J.P. Moore et al., HIV Molecular Immunology Database, Theoretical Biology and Biophysics Group, Los Alamos National Laboratory, Los Alamos NM (2000).

[57] B. Peng and M. Robert-Guroff, Immunol Lett 78 (2001), pp. 195-200.

[58] X. Liang, T. Fu, H. Xie, E.A. Emini and J.W. Shiver, Vaccine 20 (2002), pp. 34133421.

[59] A.P. Rice and F. Carlotti, J Virol 64 (1990), pp. 1864-1868.

[60] C.L. Kuiken, B. Foley, B. Hahn, B. Korber, F. McCutchan and P.A. Marx et al., HIV Molecular Sequence Database, Theoretical Biology and Biophysics Group, Los Alamos National Laboratory, Los Alamos, NM (2000).

[61] P.G. Balboni, R. Bozzini, S. Zucchini, P.C. Marconi, M.P. Grossi and A. Caputo et al., J Med Virol 41 (1993), pp. 289-295.

[62] A. Caputo, M.P. Grossi, R. Bozzini, C. Rossi, M. Betti and P.C. Marconi et al., Gene Ther 3 (1996), pp. 235-245.

[63] C. Rossi, P.G. Balboni, M. Betti, P.C. Marconi, R. Bozzini and M.P. Grossi et al., Gene Ther 4 (1997), pp. 1261-1269.

[64] F. Gao, D.L. Robertson, C.D. Carruthers, S.G. Morrison, B. Jian and Y. Chen et al., J Virol 72 (1998), pp. 5680-5698. 
[65] V.A. Novitsky, M.A. Montano, M.F. McLane, B. Renjifo, F. Vannberg and B.T. Foley et al., J Virol 73 (1999), pp. 4427-4432.

[66] C.M. Rodenburg, Y. Li, S.A. Trask, Y. Chen, J. Decker and D.L. Robertson et al., AIDS Res Hum Retrovir 17 (2001), pp. 161-168.

[67] M.O. Salminen, B. Johansson, A. Sonnerborg, S. Ayehuni, D. Gotte and P. Leinikki et al., AIDS Res Hum Retrovir 12 (1996), pp. 1329-1339.

[68] L.H. Ping, J.A. Nelson, I.F. Hoffman, J. Schock, S.L. Lamers and M. Goodman et al., J Virol 73 (1999), pp. 6271-6281.

[69] L.J. Seigel, L. Ratner, S.F. Josephs, D. Derse, M.B. Feinberg and G.R. Reyes et al., Virology 148 (1986), pp. 226-231.

[70] C. Neuveut and K.T. Jeang, J Virol 70 (1996), pp. 5572-5581.

[71] Jeang KT, Smith SM, Pentlicky S, Neuveut C, Marx P, Abstract No WeOrA1256. XIV International AIDS Conference, Barcelona, Spain 2002.

[72] K. Verhoef and B. Berkhout, J Virol 73 (1999), pp. 2781-2789.

[73] H.M. Craig, M.W. Pandori and J.C. Guatelli, Proc Natl Acad Sci USA 95 (1998), pp. $11229-11234$. 